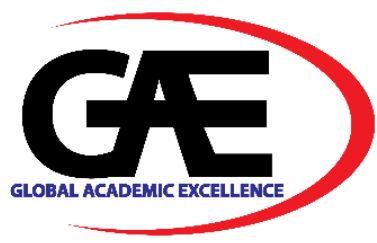

\title{
A PRELIMINARY SURVEY STUDY ON THE RECEPTION OF INDOOR HYDROPONICS SYSTEM FOR LOW-INCOME HOUSEHOLD IN SELANGOR
}

\author{
Nurul Maisarah Hamdan ${ }^{1 *}$, Mohamad Hanif Md Saad ${ }^{2}$, Ang Mei Choo ${ }^{3}$ \\ 1 Institute of IR 4.0 (IIR4.0), Universiti Kebangsaan Malaysia, Malaysia \\ Email: p110772@siswa.ukm.edu.my \\ 2 Institute of IR 4.0 (IIR4.0), Universiti Kebangsaan Malaysia, Malaysia \\ Email: hanifsaad@ukm.edu.my \\ 3 Institute of IR 4.0 (IIR4.0), Universiti Kebangsaan Malaysia, Malaysia \\ Email: amc@ukm.edu.my \\ Corresponding Author
}

\section{Article Info:}

Article history:

Received date: 10.06 .2021

Revised date: 15.07.2021

Accepted date: 20.08.2021

Published date: 01.09.2021

\section{To cite this document:}

Hamdan, N. M., Md Saad, M. H., \& Ang, M. C. (2021). A Preliminary Survey Study On The Reception Of Indoor Hydroponics System For Low-Income Household In Selangor. Journal of Information System and Technology Management, 6 (22), 171-187.

DOI: $10.35631 /$ JISTM.622014

This work is licensed under CC BY 4.0

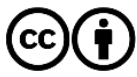

\begin{abstract}
:
Indoor hydroponics system is gaining acceptance and traction in providing practical indoor farming capabilities for urban dwellers, including in low income housing estates. However, for the low income urban dwellers, the size of their residence might restrict the design of the indoor hydroponics system, especially in terms of available floor space. Furthermore, before one starts to develop an indoor hydroponics system, it is imperative to identify users' preferences, in terms of the types of plants to grow, price, and design to enable the researchers to develop a better indoor hydroponics system. In this study, opinions from 53 participants on indoor hydroponics systems were obtained and analysed. Four aspects were analysed via the survey: (1) customer evaluations; (2) positive value; (3) costing; and (4) purchasing proclivity. The study shows that participants prefer to grow edible plants because of their benefits. Participants also prefer systems priced at below RM100 (60.40\% of the respondent). Aloe Vera (56.6\% preference) and Brazilian Spinach(49.1\% preference) are two types of plants most preferred by the participants. As mentioned previously, the output of this survey will be used to guide the process of developing a suitable indoor hydroponics system for the low-income urban dwellers.
\end{abstract}

Keywords:

Hydroponics; Smart Farming; Agriculture; Food Supply, Vertical Farming 


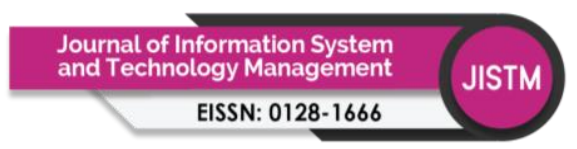

Volume 6 Issue 22 (September 2021) PP. 171-187 DOI: 10.35631/JISTM.622014

\section{Introduction}

In recent years, growing plants indoors in water containing dissolved nutrients has become increasingly common and widespread. Hydroponics has proven to be an outstanding alternative crop production method, as well as a highly challenging and exacting system that ensures improved crop production. An indoor growing system allows for a significant reduction in fertilizer application as well as a significant reduction, if not total removal, of nutrient leaching from greenhouses into the atmosphere (Modu, Adam, Aliyu, Mabu, \& Musa, 2020; Zamanipour, Ganji Moghaddam, Tehranifar, \& Abedi, 2019). When compared to plants grown with chemical fertilizer, conventional farming requires the farmer to spend the full amount of time on the farmland, and organic manure is applied to the farmland, which leads to healthier soil, higher yield, and a plant that is robust and beneficial. Traditional farming uses the soil for several years, and expanded chemical fertilizer use destroys the micro flora and micro fauna that exist in the soil. Farmers are unaware of the chemical fertilizer and pesticide limits for farmland, which has a negative impact on the environment. Most food is made and processed significant distances away and miraculously appears on store shelves for our usage. Urban farming provides a tangible, affordable potential for city residents into becoming active in the topic of food provenance and food security, and to reconnect with a food system that many feel is out of their reach (Ackerman, 2012).

Malaysia is a developing nation, so many structures have been built and are now in the process of being built. It allows a large city like Kuala Lumpur to become a compact city with growth and residents. The area or space available for farming activity grows day by day, such that large-scale agricultural projects in Kuala Lumpur would be unable to keep up with the city's rapid growth (Talib, Aidil Azlin, \& Dollah, n.d.). Through this study, a questionnaire was conducted to see the participants' interest and suitability for vegetable cultivation activities for their own use as well as small-scale commercial use in the house through automated vertical farming. The benefit of hydroponic food crops is that they do not need soil content or a large amount of land for cultivation, rather it can be achieved in a small space using water resources. Each hydroponic crop is also pesticide-free, making it healthier to eat (Herman \& Surantha, 2019; Zamanipour et al., 2019). Urban farming systems, mostly implemented in hydroponic form, are now seen as a feasible alternative to the minimal land area suitable for farming, as well as more practical use of water supplies, to provide better prospects for a sustainable food supply in both developed and developing countries, in tandem with urbanization and modern city growth (Besthorn, 2013; Daniel, 2014).

Hydroponics is a technology that is considered a crucial component of Vertical Farming (VF) (Beacham, Vickers, \& Monaghan, 2019; Miller, 2018). Hydroponics is a method of growing plants without the need of soil. Rather than having their roots held and nourished by soil, plants are frequently irrigated and maintained with the help of an inert developing medium such as rock-wool, and provided with nutrient-rich water that is essential for plant growth. Hydroponic buildings utilize 60-70 percent less water than traditional farming methods (Despommier, 2019; Royston \& Pavithram, 2018). Several types of hydroponics systems, including automated indoor hydroponics system are actively being developed by researchers all over the world (Rahimi et. Al, 2020). VF is a viable method that allows for the production of vast amounts of crop production and medicinal plants in a very small space using just modern technology (Kalantari, Mohd Tahir, Mahmoudi Lahijani, \& Kalantari, 2017). A considerable number of VF systems utilizes hydroponics as a way to provide suitable system 
to plant vegetation's. The worldwide VF demand has been continuously growing in recent years as populations have grown, and urban life has become more frequent in metropolitan areas. The VF market was valued at $\$ 4.4$ billion in 2019, but it is expected to grow to $\$ 15.7$ billion by 2025 (Saad et al, 2021). Vertical agriculture's appeal in large cities is enhanced by the ability to employ vertical space and eliminate the demand for additional land and building activities. Due to the growing popularity of organic foods, VF demand is likely to skyrocket (M. Shahbandeh, 2020).

A survey was developed to identify few aspects: (1) To investigate the majority options between food plants or ornamental plants by the consumer; (2) To identify the type of indoor plant; (3) To clarify the estimated amount of time a user could spend on planting to suit their needs; (4) To determine the knowledge of the user on urban farming; (5) To determine the importance of an indoor planting system based on user perspective; (6) To find the suitable price that the consumer can spend; (7) To acknowledge whether the user will buy and start indoor farming if there is a suitable farming module. The model and hypotheses for this analysis are depicted in Figure 1.

\section{A1}

Consumer perceptions of knowledge and need characteristics can have a substantial and beneficial impact on how they view the system's benefits.

A2

Consumer perceptions of their knowledge and needs can have a substantial and beneficial impact on their ability to purchase.

\section{A3}

Consumer perceptions of the cost of indoor farming can have a substantial and beneficial impact on their positive value of consumption.

\section{A4}

Consumer perceptions of pricing can have a major and detrimental impact on their proclivity to purchase.

\section{A5}

Consumer perceptions of hydroponic goods would have a substantial and beneficial impact on their proclivity to purchase.

We expected that consumer evaluation would be affected by the knowledge and needs of the user. We also expected that the overall consumers' evaluation and perceived pricing of the hydroponic system would significantly influence their perceptions of product benefits and their willingness-to-buy. With the current study, our aim was to address these questions and provide a more general idea for early-stage about the state of art of indoor hydroponic system research in Selangor, Malaysia. 


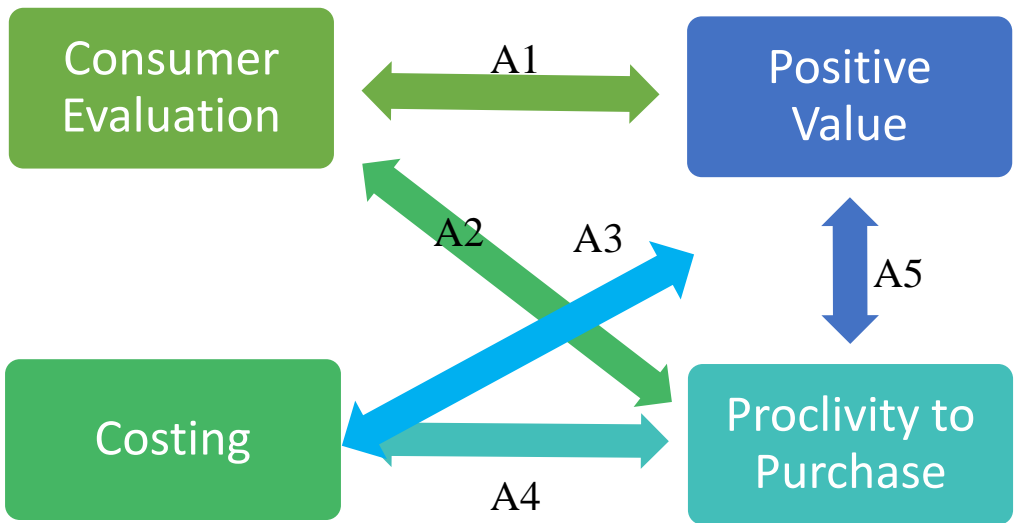

Figure 1: The Study's Conceptual Framework

The primary survey focus was on the functionality of product development in the further study. Although there is no precise way to measure modularity, Baldwin (2012) notes that devices can be divided into two categories: highly modular systems comprised of numerous, compact, loosely connected modules, and non- modular systems comprised of a single, broad structure in which "everything is dependent on everything else". Table 1 analyzed 3 types of indoor planting modules in the current market which were chosen as references. The aim was to condense the state-of-the-art data while also providing an accurate summary of the available types of goods on the market. 
Table 1: Analysed 3 Indoor Hydroponic Modules on the Market for Reference in Designing the System for Low-Income Household

\section{INDOOR \\ PLANTING \\ MODULE} DETAILS

\section{PHOTO}

NAAVA

Module

(Mustonen, 2017)
Herbert

Module

(Penzias, Lobato-

Jimenez, Boubachta, \& Orosz, 2019)
NAAVA is a kind of green wall that is leased to offices, festivals, and other venues. It is intended to provide hydroponics as a process rather than a commodity, with the company handling transportation, construction, and plant treatment. As a result, the volume is very high, weighing $1 \mathrm{~m} \times 0.35 \mathrm{~m} \times 3 \mathrm{~m}$; [m3]. With such a vast footprint comes a huge number of rising spots, with each unit containing between 30 and 50 crops. It is difficult to say precisely because the construction is carried out by technicians deployed by the organization on-site, but by physically examining various devices up close, it seems to be a relatively simple operation, the only stumbling block being the system's scale. This product differs from the others studied in that it is not intended for home use and is not intended for commercial use since it only crops indoor plants.

Herbert is a product that is mostly intended for home cultivation and has no commercial applications at the moment. Measuring $0.56 \mathrm{~m} \times 0.115 \mathrm{~m} \times 0.82 \mathrm{~m}$; [m3], it contains a total of 15 seeds. The product is not constructed with modularity in mind, nor is it built with the intention of conveniently scaling the device up. The product includes an interface that provides detailed information about the lifecycles of various plants and the reservoir's water level. Herbert's assembly process is relatively straightforward, requiring only installing a rail to the wall and the hanging of the product.
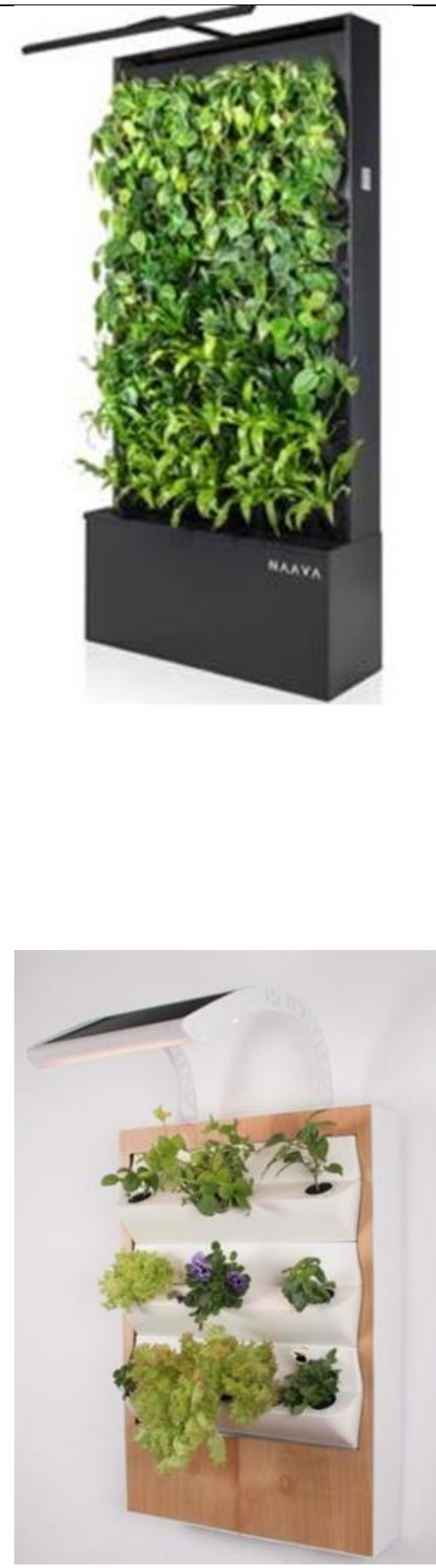
IKEA Växer

(Aouf, 2016)
The IKEA Växer is a mini hydroponic system with a measurement of $0.44 \mathrm{~m} \mathrm{x}$ $0.25 \mathrm{~m} \times 0.42 \mathrm{~m}$; [m3]. This module consists of only 8 growing spots in total. It is a module specifically designed for the household. In true IKEA style, the Växer epitomizes simplicity.

\section{Methodology}

A survey was conducted for a low-income household in Selangor. Selangor has 9 districts: Gombak; Hulu Langat; Hulu Selangor; Klang; Kuala Langat; Kuala Selangor; Petaling; Sabak Bernam and Sepang, as shown in Figure 2. The questionnaire survey was used to obtain data from residents. Fifty-three households (desired sample size, $n=53$ ) from diverse backgrounds were selected from residents across Selangor. A household questionnaire was created to gather data on the restructured determinants of livelihood diversification as shown in Table 2. The survey, which had 14 questions in few categories, was based on consumer evaluations, costing, positive value, and willingness to buy the indoor hydroponic system.

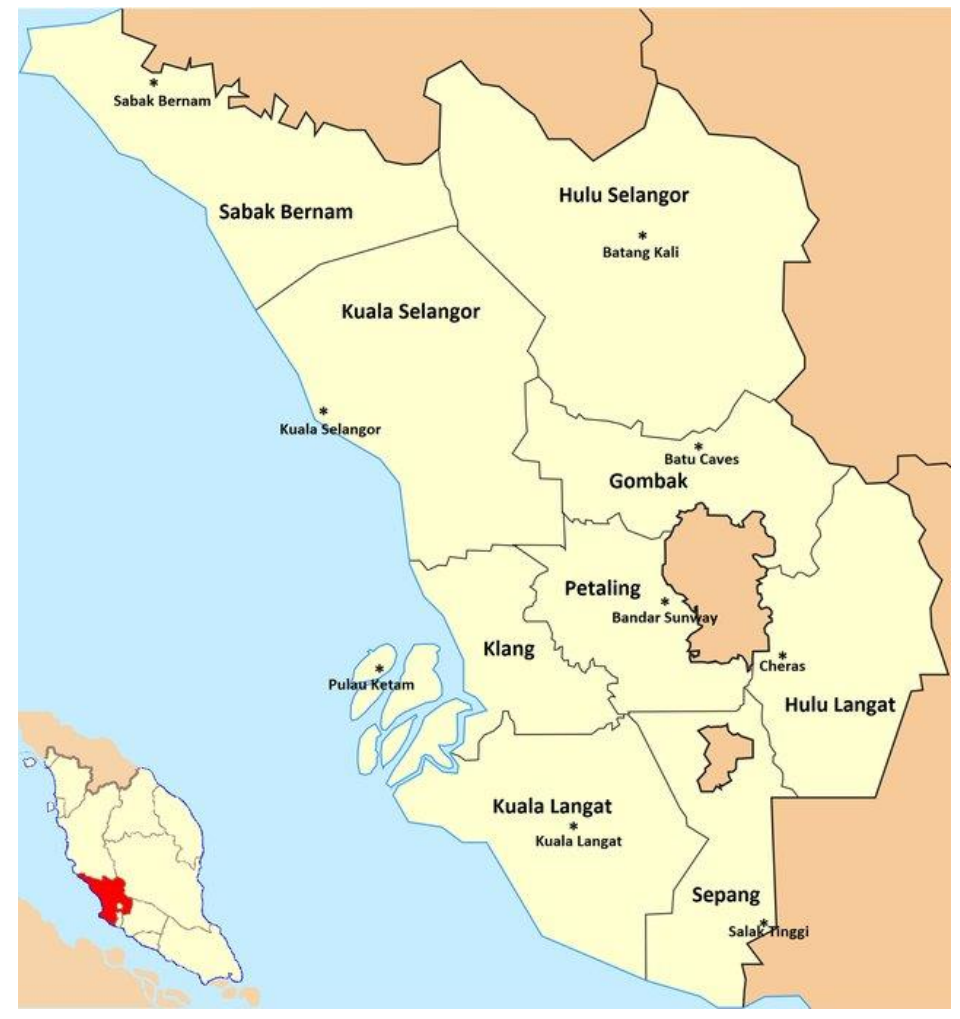

Figure 2: Location of the Selangor, Malaysia 


Table 2: Five Factors with 14 Questionnaire Leading To Livelihood Diversification
Were Used To Establish Survey Questions
Contributing Factors

\section{Result}

Data from 53 participants were collected and analyzed in this study. Figure 3 represents the general question on if the consumers have any plant in their house. The majority of the participants stated that they had already planted trees, with $84.9 \%$ (45 participants), and $15.1 \%$ (8 participants) did not have any plant in their house.

\section{RESPONDENT WITH PLANT IN HOUSE}

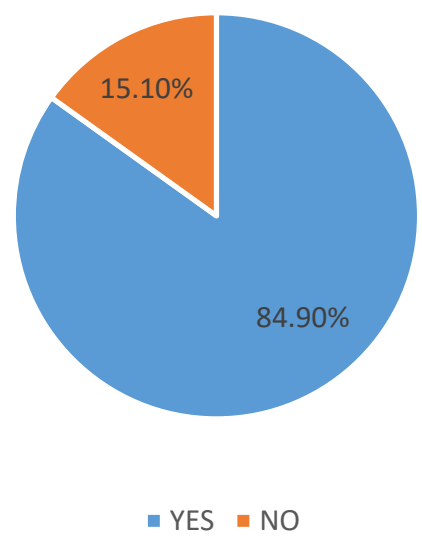

Figure 3: Shows If the Respondent Has Any Plant 
Hydroponics delivers nitrogen and water straight to the roots. This allows the shoot structure of the plants to develop more rapidly, resulting in increased foliage, larger fruits, flowers, and other edible parts (Wahome, Oseni, Masarirambi, \& Shongwe, 2011). The type of plant between food plants and flower plants plays a vital role for the consumer to identify the majority type plant chosen by the respondent. Figure 4 shows that the large part of respondents chose food plant with 56.6\% (30 participants), as compared to flower plant with $52.8 \%$ (28 participants).

\section{TYPE OF PLANT PREFERRED}

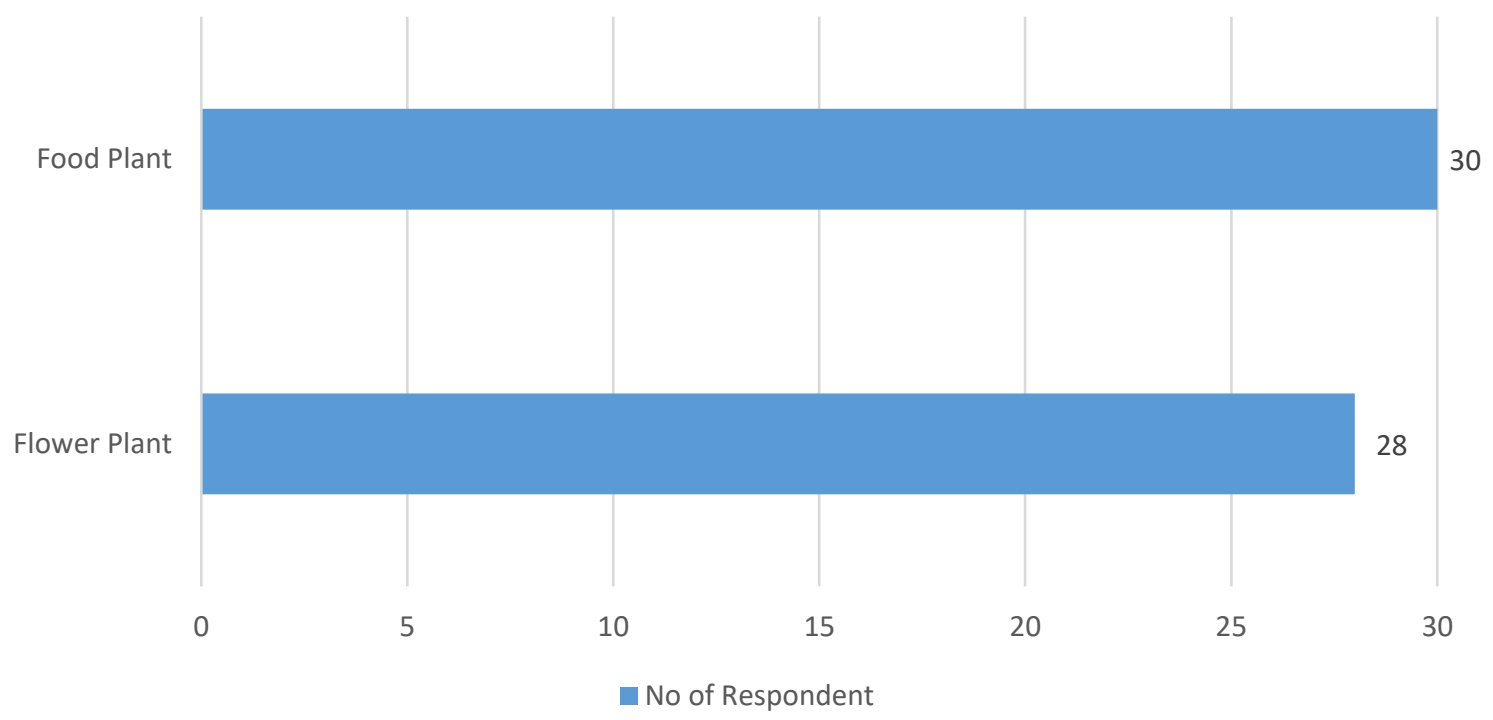

Figure 4: Shows the Type of Plant Preferred Between Food Plant and Flower Plant by the Respondent

Regarding participating response on their interest in planting ornamental and food trees indoors, the results showed that $71.7 \%$ (38 participants) were interested in planting a flower tree, while $77.4 \%$ (41 participants) were interested in planting a food tree, as shown in Figure 5 and Figure $6.51 .1 \%$ (8 participants) were not interested in planting flower trees, and $13.2 \%$ (7 participants) out of 52 participants stated that they were unsure of planting the flower tree. Meanwhile, there were $18.9 \%$ (10 participants) who were not interested in planting food trees, and only $3.8 \%$ ( 2 participants) of them stated that they were unsure. 


\section{INTERESTED IN PLANTING FLOWER TREE}

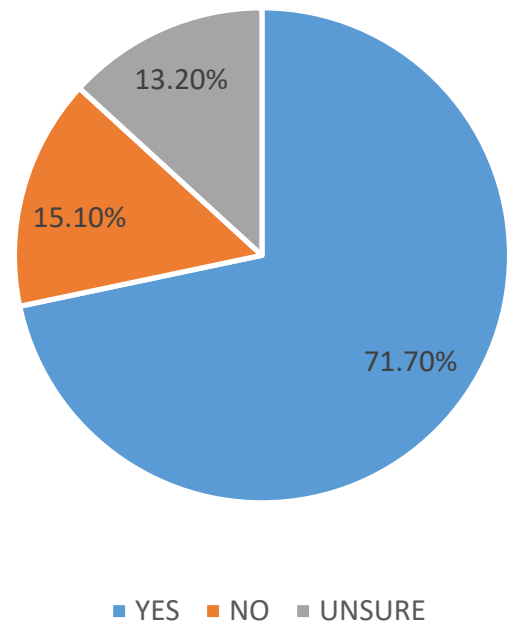

Figure 5: Shows the Percentage of Participants Who Are Interested In Planting Flower Tree Indoor

INTERESTED IN PLANTING FOOD TREE

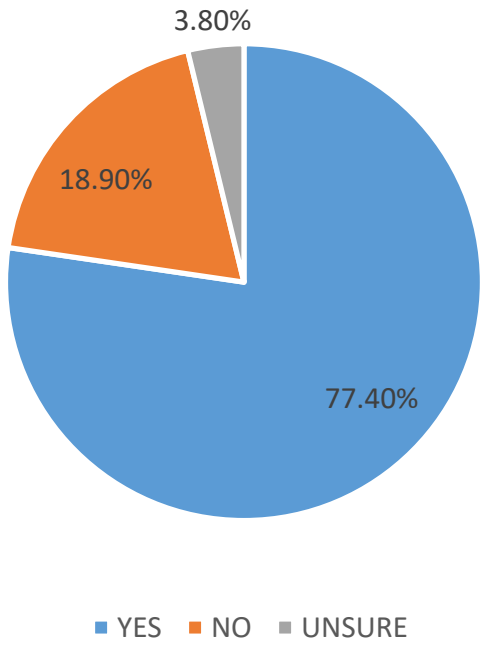

Figure 6: Shows the Percentage of Participants Who Are Interested In Planting Food Tree Indoor

Based on the survey conducted, the majority of the participants, with $49.1 \%$ (26 participants) stated that there is no need to spend much time managing and controlling the planting process. In comparison, 43.4\% (23 participants) stated yes and agreed that much time was needed to manage the plants, while $7.5 \%$ (4 participants) responded as being unsure, as shown in Figure 7. 


\section{CONSUMER OUTLOOK OVER TIME SPENDING FOR THE} PLANT

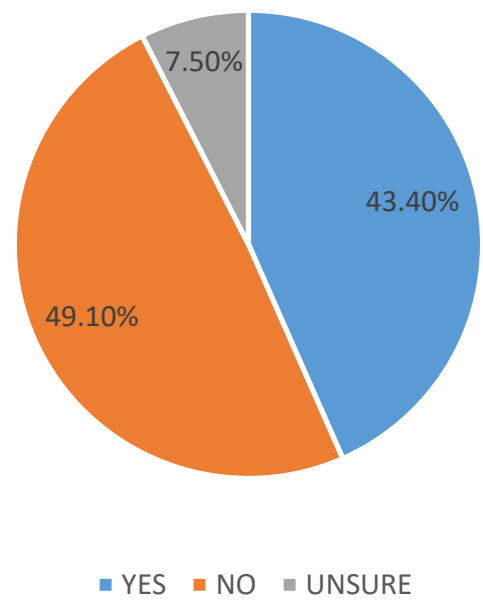

Figure 7: Shows the Consumer Point of View on Time They Need Spend For the Plant

There are 7 different time ranges as shown in Figure 8, for the respondents in estimating the amount of time they can spend on planting their trees to fit their needs. There was only one respondent with $1.9 \%$, who stated that he/she would need more than 10 hours/week. Most of the respondents declared they would need around 1-2 hours/week to spend for managing the plants, with $34 \%$ (18 participants). Other than that time range, $0-1$ hour/week showed $24.5 \%$ (13 participants), 2-3 hours/week showed 17\% (9 participants), 3-5 hours/week showed $13.2 \%$ (7 participants), 5-10 hours/week showed $5.7 \%$ (3 participants), and $3.8 \%$ (2 participants) were unsure on how much time they needed to spend for a plant.

\section{ESTIMATED TIME NEEDED FOR THE PLANT}
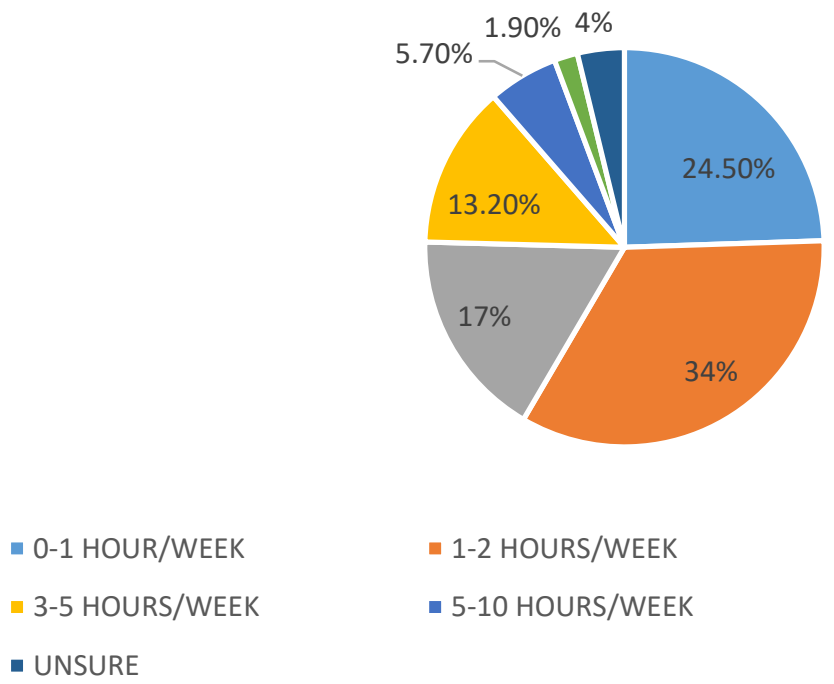

Figure 8: Indicate the Estimated Time Need to Spend For the Plant by the Respondent 
Volume 6 Issue 22 (September 2021) PP. 171-187 DOI: 10.35631/JISTM.622014

Figure 9 expresses the respondents' opinions on if the plant can help in their daily cooking. It shows that a more significant number of the respondents stated that they agreed, with $79.2 \%$ (42 participants), that plants can help in their daily cooking. 9.4\% (5 participants) did not agree with the statement, and $11.3 \%$ (6 participants) were unsure of whether the plant can be used in their cooking.

\section{RESPONDENTS' OPINION IF THE PLANT CAN HELP WITH \\ DAILY COOKING}

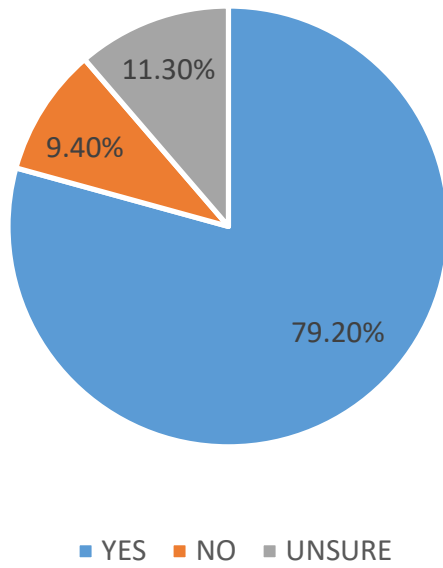

Figure 9: Specify the Participants' Opinion Whether the Plant Can Help With Their Daily Cooking or Not

Most of the respondents indicated that they agreed that the plant could be sold to their friends as a side income, with $47.2 \%$ (25 participants), as shown in Figure $10.32 .1 \%$ (17 participants) did not agree and 20.8\% (11 participants) were unsure if the plant could be sold to others.

\section{RESPONDENTS' OPINION IF THE PLANT COULD BE SOLD TO OTHERS}

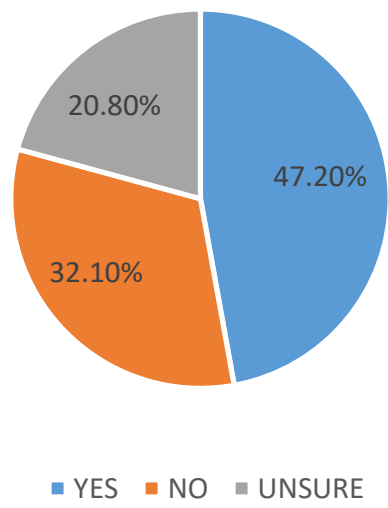

Figure 10: Shows the Participants' Opinion Whether the Plant Could Be Sold to Others 
Knowledge and information about indoor hydroponic systems are essential to overcome any mistake and wastage for the beginner. Based on the study and as shown in Figure 11, 43.4\% (23 participants) have not heard about the indoor planting system. This value is almost less than half of the respondents who do not have any knowledge on this issue. 56.6\% (30 participants) have heard about this indoor hydroponic system.

\section{RESPONDENT KNOWLEDGE ON INDOOR HYDROPONICS SYSTEM}

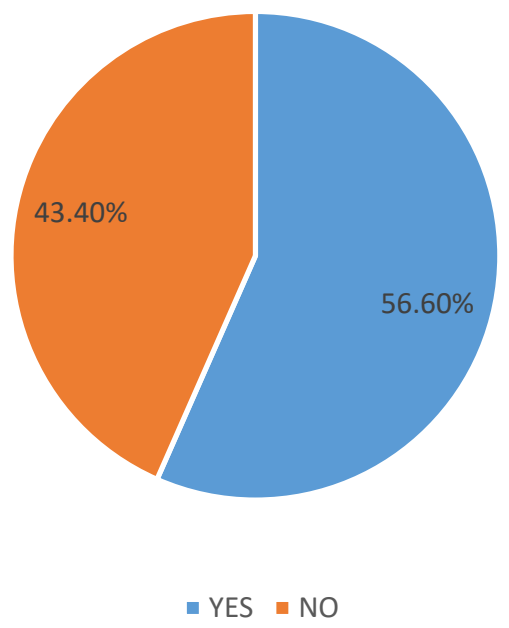

\section{Figure 11: Indicate Whether the Participants Have Knowledge or Heard About the System}

The majority of the respondents, with $77.4 \%$ (41 participants), did not survey the price of the indoor planting system, and only $22.6 \%$ (12 participants) of them surveyed it, as express in Figure 12. Meanwhile, Figure 13 shows that the price range that a consumer would be willing to pay for the system. No participant would be willing to pay the system with a cost of RM500-RM1000. Most of the participants, with $60.4 \%$ (32 participants), agreed to pay less than RM100. For the price range between RM100-RM500, 30.2\% (16 participants) mentioned that they would consider to buy, and only $9.4 \%$ of the respondents were willing to pay any price. 


\section{PRICE SURVEY BY RESPONDENT}

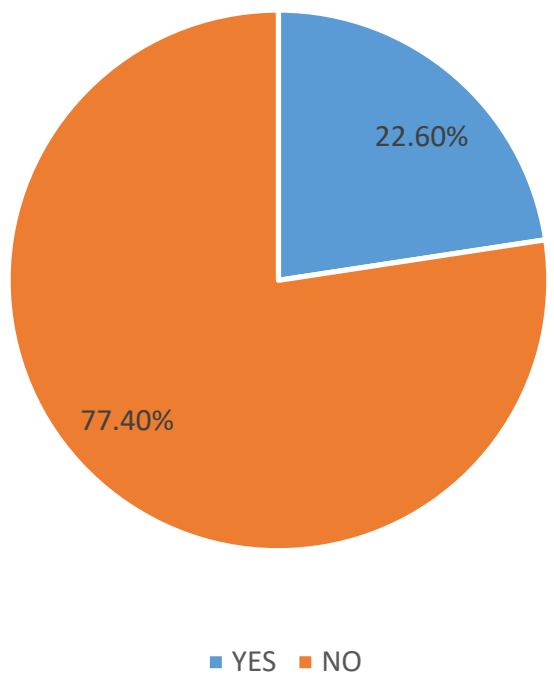

\section{Figure 12: Shows If the Participants Did the Survey on the Price of the Indoor Hydroponics System}

\section{RANGE PRICE RESPONDENT WILLING TO PAY FOR THE SYSTEM}

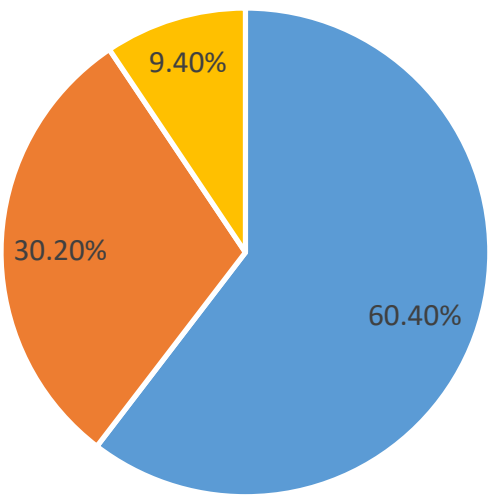

- LESS THAN RM100 - RM100-RM500 - RM500-RM1000 - WILLING TO PAY ANY PRICE

Figure 13: Express the Range Cost Participants Willing to Pay For the System

The type of plant needs to be determined by the consumer to comply with their needs and usage. There are around 16 types of trees that the respondents thought would be suitable to plant indoors. Figure 14 shows the types of plants considered by the consumer. The top 6 plants with a high percentage are Aloe Vera, Brazilian Spinach, Green Chili, Mint, Soup Leaf and Green Mustard, with 56.6\%, 49.1\%, 47.2\%, and 30.2\%, respectively. 


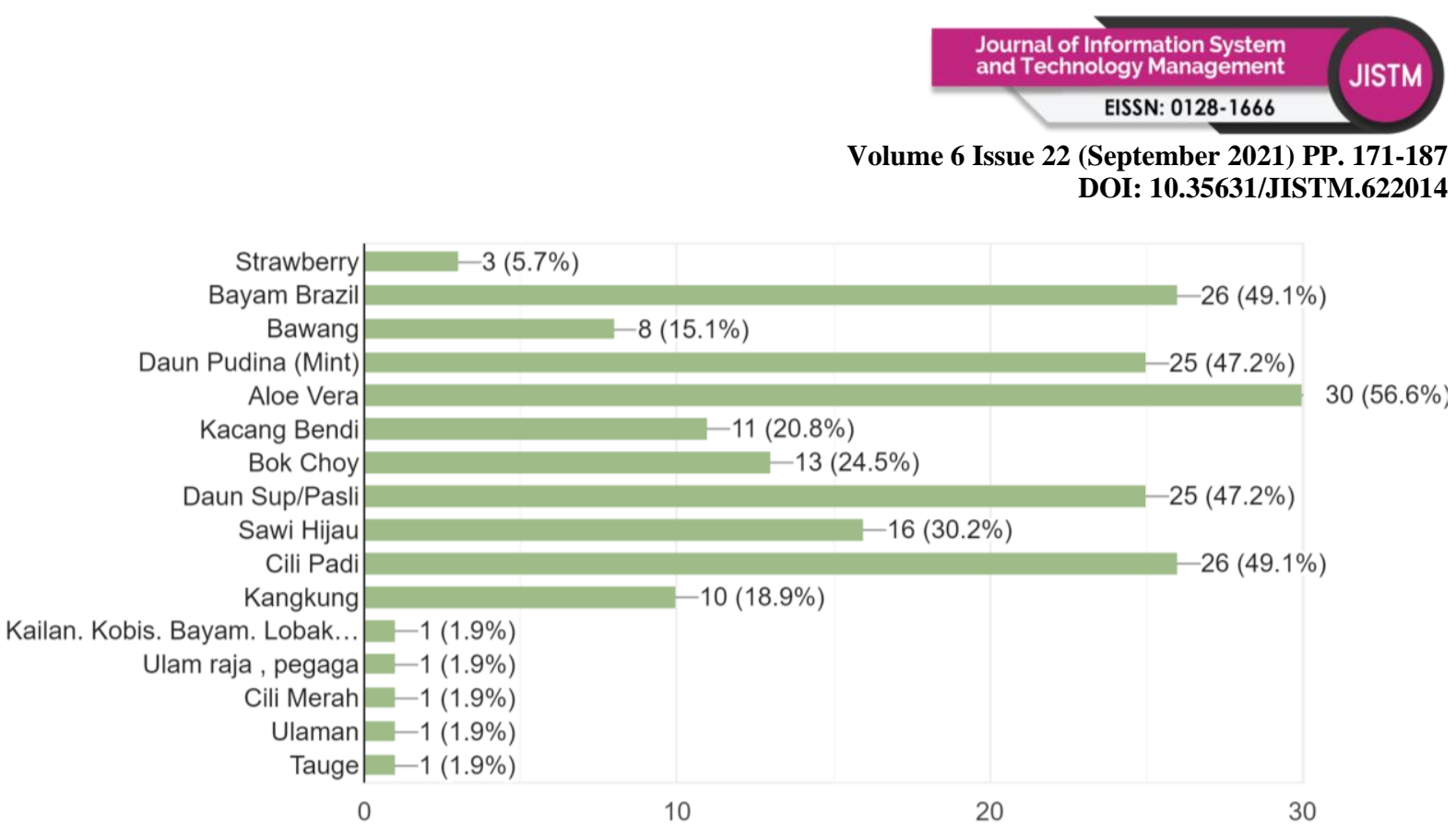

Figure 14: Indicate 16 Types of Plant Chosen by the Participants That Full Fill Their Need and Used

Based on Figure 15, majority of the respondents, with $62.3 \%$ (33 participants), stated that they think their house has a suitable space to implement the process of planting in the house, while $24.5 \%$ of them said that they do not have a suitable space, and $13.2 \%$ were unsure.

\section{RESPONDENTS' OPINION IF THE PLANT COULD BE SOLD TO OTHERS}

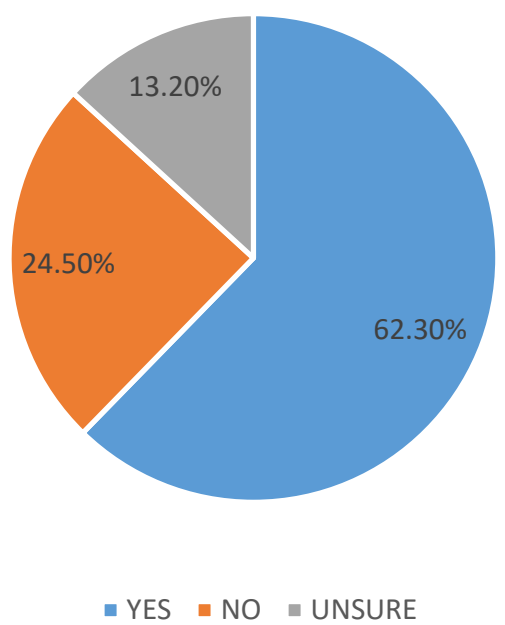

Figure 15: Shows the Participants Who Think Their House Has a Suitable Space to Implement the Process of Planting Indoor

The consumer's willingness to buy is the last aspect of producing an optimized and efficient indoor hydroponics system. The survey shows that $81.1 \%$ of the respondents are willing to buy the system if there is a suitable module to plant fruits, vegetables, and flowers indoors, 
while only $7.5 \%$ of them do not want the module, and $11.3 \%$ are unsure, as shown in Figure 16 below.

\section{RESPONDENTS WILLINGNESS TO USE AND BUY IF THERE IS A SUITABLE MODULE AVAILABLE}

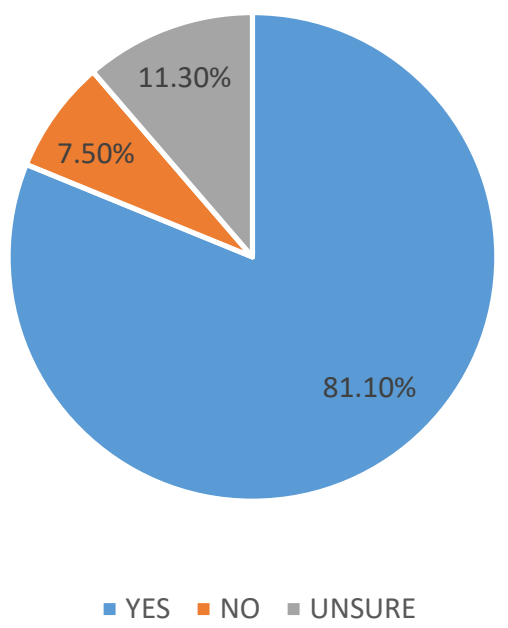

\section{Figure 16: Express the Participants' Willingness to Buy and Use the Indoor Hydroponics System If There Is a Suitable Module Available}

\section{Conclusion}

This survey overviews the preliminary study of the relationship between consumer evaluations, costing, positive value, and proclivity to purchase, to produce the most efficient and suitable indoor hydroponic farming system for the low-income household at Selangor. Identifying what drives people to buy food will help food producers and retailers better target their customers and remain competitive in the market (Chen, Tong, Tan, \& Kong, 2020). The outcome based on this study can be used and would be beneficial for developing the optimized indoor hydroponics system in the future. As shown in the results, the food plant is the main consumer choice because of the high advantages when compared to a flower plant. Other than that, the result of the price range below RM100 is one of the guidelines that will be used while designing the system. The type of plant: Aloe Vera, Brazilian Spinach, Green Chili, Mint, Soup Leaf, and Green Mustard also plays an essential role in developing the indoor system, as it can be used to analyze the optimized yield index to maximize the crop production. Lastly, a suitable place can be used to create an advanced design like the vertical farming design to save house space. Based on the research study, their knowledge and needs affected user evaluation. As shown in the respondents' opinion result, $79.2 \%$ of the participants agree that a plant can help with their daily cooking. It was also stated that the overall consumers' evaluation and perceived pricing of the hydroponic system would significantly influence their perceptions of product benefits and their willingness-to-buy, with $81.1 \%$ of the participants being able to purchase the product. With the current study, we aimed to address these questions and provide a more general idea for an early stage about the state of the art of indoor hydroponic system research in Selangor, Malaysia. More research is required to understand how studying food security in the sense of compassion can raise awareness of these problems, motivate information acquisition, and affect improvements in food-handling behaviors. Research and development on the best indoor hydroponics system 
design for low-income households in Selangor also needs to be done in the future for further study.

\section{Acknowledgement}

The authors wish to acknowledge the financial support for this work from the Ministry of Higher Education of Malaysia via the research grant LRGS/1/2019/UKM-UKM/5/2.

\section{References}

Ackerman, K. (2012). Urban agriculture: Opportunities and constraints. Metropolitan Sustainability: Understanding and Improving the Urban Environment, 118-146. https://doi.org/10.1533/9780857096463.2.118

Aouf, R. S. (2016, May). IKEA moves into indoor gardening with hydroponic kit. Retrieved May 20, 2021, from https://www.dezeen.com/2016/05/03/ikea-indoor-gardeninghydroponic-kit-krydda-vaxer/

Beacham, A. M., Vickers, L. H., \& Monaghan, J. M. (2019). Vertical farming: a summary of approaches to growing skywards. Journal of Horticultural Science and Biotechnology, 94(3), 277-283. https://doi.org/10.1080/14620316.2019.1574214

Besthorn, F. H. (2013). Vertical Farming: Social Work and Sustainable Urban Agriculture in an Age of Global Food Crises. Australian Social Work, 66(2), 187-203. https://doi.org/10.1080/0312407X.2012.716448

Chen, H., Tong, X., Tan, L., \& Kong, L. (2020). Consumers' acceptability and perceptions toward the consumption of hydroponically and soil grown broccoli microgreens. Journal of Agriculture and Food Research, 2, 100051. https://doi.org/10.1016/j.jafr.2020.100051

Daniel, P. (2014). Contribution of Vertical Farms to Increase the Overall Energy Efficiency of Urban Agglomerations. Journal of Power and Energy Engineering, 02(04), 82-85. https://doi.org/10.4236/jpee.2014.24013

Despommier, D. (2019). Vertical farms, building a viable indoor farming model for cities. Retrieved June 9, 2021, from https://journals.openedition.org/factsreports/5737

Herman, \& Surantha, N. (2019). Intelligent monitoring and controlling system for hydroponics precision agriculture. 2019 7th International Conference on Information and Communication Technology, ICoICT 2019, (April). https://doi.org/10.1109/ICoICT.2019.8835377

Kalantari, F., Mohd Tahir, O., Mahmoudi Lahijani, A., \& Kalantari, S. (2017). A Review of Vertical Farming Technology: A Guide for Implementation of Building Integrated Agriculture in Cities. Advanced Engineering Forum, 24, 76-91. https://doi.org/10.4028/www.scientific.net/aef.24.76

M. Shahbandeh. (2020). Forecast for vertical farming market global 2025 | Statista. Retrieved June 9, 2021, from https://www.statista.com/statistics/487666/projection-verticalfarming-market-worldwide/

Miller, A. (2018, April). Vertical farming and hydroponics on the spectrum of sustainability Sustainable Food Trust - Sustainable Food Trust. Retrieved June 9, 2021, from https://sustainablefoodtrust.org/articles/vertical-farming-and-hydroponics-on-thespectrum-of-sustainability/

Modu, F., Adam, A., Aliyu, F., Mabu, A., \& Musa, M. (2020). A survey of smart hydroponic systems. Advances in Science, Technology and Engineering Systems, 5(1), 233-248. https://doi.org/10.25046/aj050130 
Mustonen, T. (2017, July). What are Green Walls - the definition, benefits, design and greenery. Retrieved May 20, 2021, from https://www.naava.io/editorial/what-aregreen-walls

Penzias, A., Lobato-Jimenez, A., Boubachta, M., \& Orosz, K. (2019). Herbert - Grow fresh organic food at home by Ponix Systems - Kickstarter. Retrieved May 20, 2021, from https://www.kickstarter.com/projects/1706256286/herbert-grow-fresh-organic-foodat-home

Rahimi, M. K. H., Saad, M. H. M, Juhari, A. H. M, Sulaiman, M. K. A. \& Hussain, A. (2020) A Secure Cloud Enabled Indoor Hydroponic System Via ThingsSentral IoT Platform, 2020 IEEE 8th Conference on Systems, Process and Control (ICSPC), 2020, pp. 214-219, doi: 10.1109/ICSPC50992.2020.9305792.

Royston, R. M., \& Pavithram, P. (2018). Vertical Farming : a Concept. International Journal of Engineering and Techniques, 4(3), 500-506. Retrieved from http://www.ijetjournal.org

Saad, M.H.M.; Hamdan, N.M.; Sarker, M.R. State of the Art of Urban Smart Vertical Farming Automation System: Advanced Topologies, Issues and Recommendations. Electronics 2021, 10, 1422. https://doi.org/10.3390/electronics10121422

Talib, H., Aidil Azlin, K., \& Dollah, S. (n.d.). ANALYZING HYDROPONIC RACK SYSTEM FOR APARTMENT HOUSE. (2016).

Wahome, P. K., Oseni, T. O., Masarirambi, M. T., \& Shongwe, V. D. (2011). Effects of Different Hydroponics Systems and Growing Media on the Vegetative Growth, Yield and Cut Flower Quality of Gypsophila (Gypsophila paniculata L.). World Journal of Agricultural Sciences, 7(6), 692-698.

Zamanipour, M., Ganji Moghaddam, E., Tehranifar, A., \& Abedi, B. (2019). Growth and Yield of Hydroponic Lettuce as Influenced by Different Growing Substrates. Azarian Journal of Agriculture, 6(1), 203-208. https://doi.org/10.29252/azarinj.003 